\title{
Nasoenteral tube: factors associated with delay between indication and use in emergency services
}

\author{
Sonda Nasoenteral: fatores associados ao delay entre indicação e uso em Emergência \\ Sonda Nasogástrica: factores asociados al delay entre indicación y uso en Servicio de Urgencia
}

Franciele Anziliero', Ana Paula Almeida Corrêa', Bárbara Amaral da Silva",
Bárbara Elis Dal Soler", Érica Batassini', Mariur Gomes Beghetto',III
'Universidade Federal do Rio Grande do Sul, Nursing School,
Postgraduate Program in Nursing. Porto Alegre, Rio Grande do Sul, Brazil.
"Universidade Federal do Rio Grande do Sul, Nursing School,
Undergraduate Program in Nursing. Porto Alegre, Rio Grande do Sul, Brazil.
I' Hospital de Clínicas de Porto Alegre, Unit Álvaro Alvim, Clinical Admission. Porto Alegre, Rio Grande do Sul, Brazil.
How to cite this article:
Anziliero F, Corrêa APA, Silva BA, Soler BED, Batassini E, Beghetto MG. Nasoenteral tube: factors associated
with delay between indication and use in emergency services. Rev Bras Enferm [Internet]. 2017;70(2):326-34.
DOI: http://dx.doi.org/10.1590/0034-7167-2016-0222

Submission: 06-22-2016

Approval: 08-15-2016

\section{ABSTRACT}

Objective: to know the time between indication and use of a nasoenteral tube (NET) and factors associated with delays. Method: A prospective cohort study that followed adults in a Brazilian emergency department, since the indication of the use of a NET, evaluating clinical variables and the work process. The Generalized Estimated Equations model was adopted to identify factors associated with the delays in each stage of the process. Results: the time between indication and use of NET was 573 (IQR: 3601,093) minutes, in 150 insertions of NET. Insertions in patients who previously did not use it; delays in the medical, nutrition, and nursing care routine; use of mechanical ventilation; noradrenaline; and fasting were factors for longer time before the use of the tube. Conclusion: the time between indication and use of NET was high, exceeding 10 hours in half of the cases. Factors related to the clinical condition of the patient and to the care management would contribute to delays.

Descriptors: Nursing Care; Emergency Medical Services; Gastrointestinal Intubation; Treatment Time; Patient Safety.

\section{RESUMO}

Objetivo: conhecer o tempo entre indicação e uso da sonda nasoenteral (SNE) e fatores associados a atrasos. Método: coorte prospectiva que acompanhou adultos de uma Emergência brasileira, desde a indicação ao uso da SNE, avaliando-se variáveis clínicas e do processo de trabalho. Adotou-se o modelo de Equações de Estimações Generalizadas para identificar fatores associados a atrasos em cada etapa do processo. Resultados: o tempo entre indicação e uso da SNE foi 573 (IQR: 360-1093) minutos, em 150 inserções de SNE. Inserções em pacientes que anteriormente não a utilizavam, retardos na rotina assistencial médica, da nutrição e enfermagem, uso de ventilação mecânica, noradrenalina e jejum foram fatores para maior tempo até o uso da sonda. Conclusão: o tempo entre indicação e uso de SNE foi elevado, excedendo 10 horas em metade dos casos. Fatores relacionados às condições clínicas do paciente e à gestão da assistência contribuiriam para atrasos.

Descritores: Cuidados de Enfermagem; Serviços Médicos de Emergência; Intubação Gastrointestinal; Tempo para o Tratamento; Segurança do Paciente.

\section{RESUMEN}

Objetivo: conocer el tiempo entre indicación y uso de sonda nasogástrica (SNG) y factores asociados a demoras. Método: cohorte prospectivo que observó adultos en Servicio de Urgencia brasileño, desde indicación hasta uso de la SNG, evaluándose variables clínicas del proceso de trabajo. Se adoptó modelo de Ecuaciones de Estimación Generalizada para identificar factores asociados a demoras en cada etapa del proceso. Resultados: el tiempo entre indicación y uso de SNG fue 573 (IQR= 360 1093) minutos, en 150 inserciones de SNG. Las inserciones en pacientes que no la utilizaban previamente, demoras en rutina de atención médica, 
de nutrición y enfermería, uso de ventilación mecánica, noradrenalina y ayuno, constituyeron factores de demora hasta uso de la sonda. Conclusión: el tiempo entre indicación y uso de SNG fue elevado, superando las 10 horas en mitad de los casos. Factores relacionados a condiciones clínicas del paciente y a gestión de atención contribuyeron a las demoras.

Descriptores: Atención de Enfermería; Servicios Médicos de Urgencia; Intubación Gastrointestinal; Tiempo de Tratamiento; Seguridad del Paciente.

\section{CORRESPONDING AUTHOR Franciele Anziliero E-mail: franziliero@hotmail.com}

\section{INTRODUCTION}

Enteral tubing is among the innumerable activities of care that are the nurse's duty ${ }^{(1-2)}$. Although the use of the nasoenteral tube (NET) seems frequent in hospitalized patients, there are few studies estimating the number of users of this device. One of them ${ }^{(3)}$, performed in a Brazilian intensive care unit, demonstrated that $40 \%$ of 907 elderly people received enteral nutrition (EN) through NET. In another study ${ }^{(4)}$, carried out in a home visit setting to elderly patients with neurological diseases ( $n=79$ ), about $60 \%$ used NET at the beginning of the study, while $37 \%$ used it at the end of follow-up. The occurrence of complications, such as loss and obstruction, justified the reduction in the use of tubes and the option for ostomies.

Complications between the indication and clinical use of the NET can occur at different moments in the process as a whole. The procedures of insertion, maintenance, and administration of therapy through NET are not exempt from risks. The positioning of the distal tip of the tube in an inadequate anatomical place can cause serious incidents or adverse events ${ }^{(5)}$, such as the infusion of diet or medications into the respiratory $\operatorname{tract}^{(6-7)}$. Barrier measures, such as checking prescription data, identification of the patient and of the therapeutic composition, access pathway to the gastrointestinal tract (GIT), and the performance of X-rays (XR) for the confirmation of tube positioning are actions indicated to prevent complications ${ }^{(1-2)}$.

With the purpose of evaluating the care of patients using NET, the following indicators are used: accidental loss of the device; obstruction rate; difference between the prescribed volume of diet and the one administered; and the proportion of nutritional evaluations in the first 24 hours of admission ${ }^{(8)}$. Although the recommendations for beginning early enteral nutritional therapy (ENT) (within the first 24-48 hours) for critical patients are well established $^{(8-9)}$, the time between the indication and the use of the enteral tube is not contemplated as an indicator, especially for patients admitted in other units rather than in intensive care.

The indications for use of an enteral tube are closely related to those clinical conditions in which the patient is not allowed, cannot, or does not want to receive a diet, medicines, and/or water by mouth ${ }^{(10)}$. Thus, in a study ${ }^{(11)}$ that evaluated the use of EN in institutionalized elderly people, the authors showed that $68.1 \%$ of the indications for feeding devices occurred in acute situations and in emergency services. There are no Brazilian studies about the indication of NET use in emergencies, but clinical practice shows that there are two distinct demands for the insertion of NET in this context: (1) from patients who search for hospital attendance, and due to an acute clinical condition receive the indication of tube insertion for the administration of medicines, water, or diet; and (2) from changes of tubes that were pulled, obstructed, or had any kind of bad functioning, in patients with chronic incapacity to be fed by mouth and, therefore, who were NET users already.

A systematic revision ${ }^{(12)}$ pointed out that the effects of overcrowding, a condition constantly identified in emergency departments, are adverse and numerous. An increase in mortality associated with the demand for attendance above capacity and worse quality of services was observed, considering the delays in the assistance processes. The same can be observed in the process between the indication and the use of NET, which does not seem to be prioritized when among multiple simultaneous demands. Little is known about how the process between the indication and the use of NET occurs, about possible delays and determinants, and about safety procedure breaches. Therefore, the present study aimed to know the time between the indication and the use of a nasoenteral tube, and factors associated with its increased use.

\section{METHOD}

\section{Ethical aspects}

The study's ethical and methodological aspects were approved by the Human Research Ethics Committee of the institution.

\section{Study design, setting, and period}

This is a prospective cohort study carried out in the emergency department of a university hospital in the south of Brazil. In this emergency department, there are four rooms or units, where the patients are placed according to their clinical features: (1) Green Observation Unit: patients of low clinical risk; (2) Orange Observation Unit: patients of intermediate risk; (3) Admission Unit: patients who are waiting for beds in the wards; and (4) Vascular Unit: unstable/severe patients. The study was developed in 2015, with the period of data collection being from April to July of the same year.

\section{Population or sample: inclusion and exclusion criteria}

Based on the retrospective study ${ }^{(13)}$ that found an average time between the indication of the tube and the administration of the first diet of $375 \pm 724$ (minimum, 6; maximum, 5760 ) minutes, the need to follow 34 procedures of NET insertion was estimated, for a level of significance of $5 \%$ and a sample power of $80 \%$. The sample was extended for 150 insertions to perform multivariate analysis.

Adults who were admitted to the emergency department and demanded a NET insertion were included, whether it was the result of a reinsertion due to obstruction, withdrawal, or inadvertent displacement during admission in the emergency department, or 
of patients that made use of NET at home and who sought the emergency department only for tube change or reinsertion. Insertions performed through endoscopy or surgical procedure in patients with some anatomical alteration that modified the digestive system, or in patients who needed ostomies were not included.

\section{Study protocol}

Data collection was carried out by three nurses and two previously trained nursing students, using a standardized instrument that included variables about the patients, physician's indication of the need for a tube, insertion procedure performed by the nurse, performance of X-ray control, release of the tube for use, and effective use, as well as data regarding the work process by the assistance teams. The instrument also contemplated the moments where each of the stages between the indication (prescription) of the NET and the effective use occurred (administration of diet, medicine, and/or water). The researchers took no intervention in the care practices, having restricted their activity to observation of the teams' actions.

The times when each intermediate stage between the insertion and use of the tube occurred (from the indication to the insertion; from the insertion to the performance of an Xray; from $X$-ray to the release by the physician for tube use; from the release until the use of NET) were determined by the clocks in the rooms where the patient was at that moment.

\section{Results analysis and statistics}

Data analysis was with respect to the variable characteristics and distribution. Gamma distribution was adopted for the evaluation of total time between the indication and use of NET and the time in each substage of the process. In these cases, the results were described through mean $\pm \mathrm{SE}$ (standard error). To identify the factors associated with the times in each of the substages between the indication and the use of a tube, a univariate analysis, followed by a multivariate analysis, was performed. For this purpose, the Generalized Estimating Equations model (GEE) ${ }^{(14)}$ was used, with gamma distribution adopted with the logarithmic link function, exchangeable work matrix, and covariance matrix of the robust estimator. For intrafactor comparison, the Bonferroni test was adopted as a post-hoc test.

In the univariate analysis, with time of each substage as a response variable, clinical variables, variables related to the established therapies, the team work processes, the number and distribution of nursing professionals, and the allocation of patients in the different units of the emergency department were evaluated. Sequentially, all variables identified a with $p$ value $<0.25$ in the univariate analysis were included in the multivariate analysis, with those with a higher $p$ value being removed from the model, until only those with a $p$ value $<0.05$ remained. The Statistical Package for the Social Sciences (SPSS) software, version 20.0, was used for all analyses.

\section{RESULTS}

One hundred and 50 procedures of NET insertion were followed in 115 patients, mainly men (52.7\%) (Figure 1), whose age was $65 \pm 17.2$ years (minimum, 20; maximum, 97 years). The demand for the emergency department was motivated by neurological $(48.7 \%)$, respiratory $(22.6 \%)$, gastrointestinal $(19.1 \%)$, or other problems $(9.6 \%)$. Regarding the clinical priority for the first medical attendance, established by the Manchester Triage System, the patients were classified into the categories very urgent $(74.8 \%)$, urgent $(15.7 \%)$, emergency $(7.8 \%)$, and no urgency $(1.7 \%)$. Systemic hypertension was the most prevalent previous disease $(51.3 \%)$, followed by neoplasias (33\%), type I and II diabetes mellitus (25.3\%), and ischemic stroke (17.4\%).

Of the total number of patients, $65 \%$ received an indication of use of a tube in the first two days of admission in the emergency department, and $45.2 \%$ were followed by a family member or someone in charge at the moment of the indication of tube insertion. The reasons for tube use indication were: sensory degradation $(40 \%)$; loss of appetite $(20.7 \%)$; presence of dysphagia (17.3\%); use of invasive or non-invasive mechanical ventilation (14.7\%); malnutrition (4\%); and reinsertion in patients who make use of a tube at home (3.3\%). In 124 of the 150 insertions, the tube was used for the administration of diet, water, and/or medications $(2.6 \%$ exclusive medications, $45.3 \%$ only diet, $34.7 \%$ diet, water and medications). In the others $(17.4 \%)$, there was no use of a tube in the period of 72 hours following insertion. It was necessary to reinsert the tube twice $(16.2 \%)$, and even three times $(5.6 \%)$ due to inadvertent withdrawal by the patients themselves, or due to displacement/accidental traction.
Patients with NET indication $(\mathrm{n}=163)$

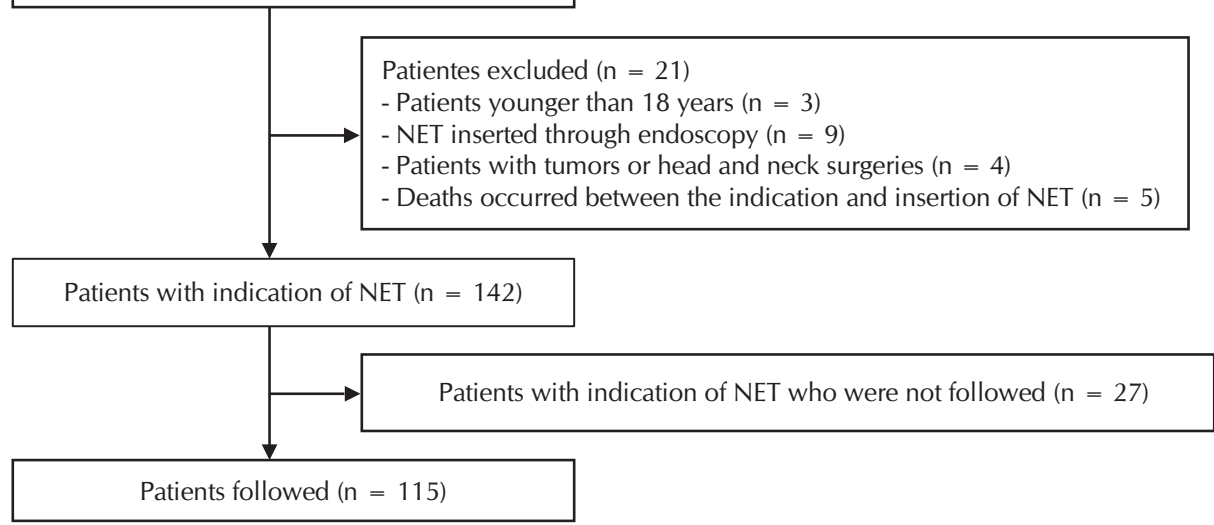

Note: NET: Nasoenteral tube; *These data refer to the number of patients, and not to the number of insertions ( $n$ $=150$ ), because there were cases of reinsertion in the same patient.

Figure 1 - Diagram of patients with indication of nasoenteral tubing followed in an emergency department, Rio Grande do Sul, Brazil, 2016* 
The median time between the indication and the use of the tube was 573 minutes (IQR: 360-1,093; minimum: 63, maximum: 3,120$)$, or approximately 10 hours. When evaluating the first substage of the process, between the indication and the insertion of the NET ( $n=150)$, the time elapsed was 49 minutes (IQR: 15-131; minimum). Both in the univariate (gross time) and the multivariate (adjusted time) analysis, less delay was identified when the patient was already using a tube at home. On the other hand, patients with sensory impairment take longer to have the tube inserted. On the occasions where the request for tubing was made verbally, it took less time than when there was a written prescription and it was not given to the nurse. Regarding the work shifts, the delay was higher during the night shift (Table 1).

In the next stage, between the NET insertion and the performance of an X-ray to confirm the anatomical positioning of the distal tip of the tube, it was possible to evaluate the data of 139 insertions, because 11 patients did not undergo an X-ray. Median time elapsed was greater that in the previous stage (103; IQR: 42182 minutes). In this stage, when inserting the NET, the nurse was able to suspect its inadequate position through auscultation, so there was less delay. In addition, time was lower for those patients who were already using a tube, and who went to the emergency department exclusively for reinsertion (Table 2).

Table 1 - Factors associated with time increase between indication and insertion of the nasoenteral tube, Rio Grande do Sul, Brazil, 2016

\begin{tabular}{|c|c|c|c|c|}
\hline Conditions & $\begin{array}{c}\text { Gross Time } \\
\text { (minutes) }\end{array}$ & $p$ value & $\begin{array}{c}\text { Adjusted Time } \\
\text { (minutes) }\end{array}$ & $p$ value \\
\hline Reason for NET Indication & & $<0.001$ & & $<0.001$ \\
\hline Loss of NET at Home ${ }^{a}$ & $28 \pm 9$ & & $57 \pm 24$ & \\
\hline MV/NIMV & $37 \pm 6$ & 0.44 & $70 \pm 14$ & 0.53 \\
\hline Malnutrition & $72 \pm 25$ & 0.05 & $93 \pm 25$ & 0.17 \\
\hline Dysphagia & $95 \pm 22$ & $<0.001$ & $166 \pm 41$ & $<0.001$ \\
\hline Loss of Appetite & $130 \pm 39$ & $<0.001$ & $195 \pm 61$ & 0.01 \\
\hline Sensory Impairment & $202 \pm 49$ & $<0.001$ & $250 \pm 54$ & $<0.001$ \\
\hline Conditions associated with the work process & & $<0.001$ & & 0.05 \\
\hline Verbal Prescription ${ }^{\mathrm{a}}$ & $89 \pm 24$ & & $72 \pm 14$ & \\
\hline No delay-associated conditions identified & $140 \pm 35$ & 0.22 & $105 \pm 20$ & 0.56 \\
\hline Prescription not given to the nurse & $266 \pm 69$ & $<0.001$ & $230 \pm 61$ & 0.02 \\
\hline Work shift & & $<0.001$ & & 0.01 \\
\hline Morning ( $7 \mathrm{am}$ to $1.15 \mathrm{pm})^{\mathrm{a}}$ & $100 \pm 14$ & & $70 \pm 11$ & \\
\hline Afternoon ( $1 \mathrm{pm}$ to $7.15 \mathrm{pm})$ & $105 \pm 29$ & 0.86 & $91 \pm 20$ & 0.36 \\
\hline Nights (7 pm to 7.15 pm) & $429 \pm 35$ & $<0.001$ & $269 \pm 109$ & $<0.001$ \\
\hline
\end{tabular}

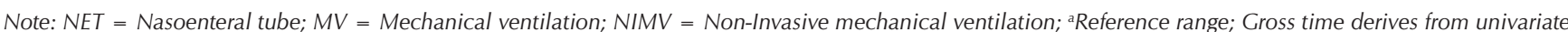
analysis, and adjusted time derives from multivariate analysis. Data expressed in "mean \pm Standard Error" of gamma distribution, in minutes.

Table 2 - Factors associated with time increase between nasoenteral tube insertion and performance of X-rays, Rio Grande do Sul, Brazil, 2016

\begin{tabular}{|c|c|c|c|c|}
\hline Conditions & $\begin{array}{c}\text { Gross Time } \\
\text { (minutes) }\end{array}$ & $p$ value & $\begin{array}{l}\text { Adjusted Time } \\
\text { (minutes) }\end{array}$ & $p$ value \\
\hline Clinical test did not indicate NET position in the GIS & $\begin{array}{c}\text { Yes: } 64 \pm 15 \\
\text { Não: } 143 \pm 96\end{array}$ & $<0.001$ & $\begin{array}{c}\text { Yes: } 29 \pm 8 \\
\text { Não: } 70 \pm 12\end{array}$ & $<0.001$ \\
\hline Loss of NET at home & $\begin{array}{c}\text { Yes: } 34 \pm 11 \\
\text { Não: } 143 \pm 13\end{array}$ & $<0.001$ & $\begin{array}{l}\text { Yes: } 22 \pm 8 \\
\text { Não: } 91 \pm 10\end{array}$ & $<0.001$ \\
\hline
\end{tabular}

Note: NET = Nasoenteral tube; GIS = Gastrointestinal system. Gross time derives from univariate analysis, and the adjusted time derives from multivariate analysis. Data expressed in "mean \pm Standard Error" of gamma distribution, in minutes. 
In the next stage, between the performance of an X-ray to confirm the anatomical positioning of the distal tip of the tube and the release of the tube by the physician, in addition to the 11 insertions which did not undergo an X-ray, 12 other insertions were excluded from the analysis because they did not have the physician's opinion about the anatomical position of the distal tip of the NET. Thus, the results at this stage refer to 127 insertions, the median time of which was 114 minutes (IQR: 52-226). Patients in the vascular unit (area for critical patients) took longer to finish this stage, when compared to those in the admission unit (patients waiting for bed in the wards). No statistical differences were found between the mean times elapsed until tube release for use when the patients were in the green units (patients of low clinical risk) or orange units (patients of intermediate risk). Again, for the patients who went to the emergency department only because of tube reinsertion, there was less delay when compared to those who had an indication for tube insertion during admission to the emergency department (Table 3).

In the last stage, between the release performed by the physician for use of the tube and effective use for therapy administration, of the 150 insertions, the tube was used in 124 of them. For patients who were discharged without using the tube for any reason (discharge from emergency, death, and fasting for 72 hours or more), mean time in this stage was 105 minutes (IQR: 43.5-319.5). It was observed that the time of use of NET for patients who needed medications through the tube was lower than for those who did not need it. The stage was faster in the afternoon shift compared to morning and night shifts, and in patients on mechanical ventilation, but not for those on noninvasive mechanical ventilation. Preliminarily, the use of noradrenaline seemed to increase this stage time. However, when adjusted for confounders, it was identified that patients who were on noradrenaline took less time. In the analysis of the variable "conditions associated with the work process," regarding the work conditions in the emergency department and possible delays, delays related with three failures in the process were identified: (1) when the physician postponed the beginning of NET, even without the patient presenting a fasting prescription, or clinical complications (a category called "NET postponed by the physician"); (2) when there were delays in the delivery of the diet by the nutrition department (a category called " $\mathrm{T}=$ time for sending the first diet by the enteral center"); and (3) when the nurse technician did not install the diet delivered by the nutrition department (a category called "diet was not installed") (Table 4).

When evaluating data of insertions where there was administration of an exclusively enteral diet, or one combined with medication and/or water ( $n=120)$, the median time between the indication of tube use and the first diet was 702 minutes (IQR: 404.5-1,331; minimum: 92, maximum: 3,752). In the insertions where patients received noradrenaline and that had the diet given through tube $(n=4)$ the median time-that is, with no adjustments for confounding variables-between the indication of NET and the first enteral diet was 1,944 minutes (IQR: 461-2,734).

Table 3 - Factors associated with time increase between the performance of X-rays and release of nasoenteral tube, Rio Grande do Sul, Brazil, 2016

\begin{tabular}{|c|c|c|c|c|}
\hline Conditions & $\begin{array}{c}\text { Gross time } \\
\text { (minutes) }\end{array}$ & $p$ value & $\underset{\text { (minutes) }}{\text { Adjusted time }}$ & $p$ value \\
\hline Room of the Emergency Service & & $<0.001$ & & $<0.001$ \\
\hline Admission Unit ${ }^{a}$ & $145 \pm 24$ & & $71 \pm 24$ & \\
\hline Orange Unit & $153 \pm 28$ & 0.55 & $78 \pm 22$ & 0.73 \\
\hline Green Unit & $202 \pm 124$ & 0.61 & $148 \pm 58$ & 0.28 \\
\hline Vascular Unit & $405 \pm 99$ & $<0.001$ & $199 \pm 77$ & $<0.001$ \\
\hline Loss of NET at home & $\begin{array}{l}\text { Yes } 57 \pm 6 \\
\text { No } 253 \pm 39\end{array}$ & $<0.001$ & $\begin{array}{l}\text { Yes } 75 \pm 37 \\
\text { No } 313 \pm 58\end{array}$ & 0.02 \\
\hline
\end{tabular}

Note: NET = Nasoenteral tube; Reference range. Gross time derives from univariate analysis, and the adjusted time derives from multivariate analysis. Data expressed in "mean \pm Standard Error" of gamma distribution, in minutes.

Table 4 - Factors associated with increased time between the release of NET for use, and the effective use for therapy administration, Rio Grande do Sul, Brazil, 2016

\begin{tabular}{lccc}
\hline \multicolumn{1}{c}{ Conditions } & $\begin{array}{c}\text { Gross time } \\
\text { (minutes) }\end{array}$ & $\boldsymbol{p}$ value & $\begin{array}{c}\text { Adjusted time } \\
\text { (minutes) }\end{array}$ \\
\hline Patients who required NET-administered medication & $\begin{array}{c}\text { Yes } 196 \pm 45 \\
\text { No } 293 \pm 35\end{array}$ & 0.13 & $\begin{array}{c}\text { Yes } 118 \pm 22 \\
\text { No } 180 \pm 37\end{array}$ \\
Work shift & & $<\mathbf{0 . 0 0 1}$ & \\
Afternoon (1 pm to 7:15 pm) & $97 \pm 19$ & & $98 \pm 21$ \\
Morning (7 am to 1:15 pm) & $538 \pm 84$ & $<\mathbf{0 . 0 0 1}$ & $231 \pm 52$ \\
Nights (7 pm to 7:30 am) & $233 \pm 45$ & $<\mathbf{0 . 0 0 1}$ & $137 \pm 29$ \\
\hline
\end{tabular}




\begin{tabular}{|c|c|c|c|c|}
\hline Conditions & $\begin{array}{c}\text { Gross time } \\
\text { (minutes) }\end{array}$ & $p$ value & $\underset{\text { (minutes) }}{\text { Adjusted time }}$ & $p$ value \\
\hline Ventilation & & $<0.001$ & & $<0.001$ \\
\hline NIMV ${ }^{a}$ & $139 \pm 44$ & & $89 \pm 24$ & \\
\hline Spontaneous & $241 \pm 36$ & 0.13 & $140 \pm 28$ & 0.07 \\
\hline MV & $444 \pm 94$ & $<0.001$ & $248 \pm 64$ & $<0.001$ \\
\hline Continuous Vasopressor & $\begin{array}{l}\text { Yes } 533 \pm 188 \\
\text { No } 238 \pm 30\end{array}$ & 0.03 & $\begin{array}{l}\text { Yes } 87 \pm 30 \\
\text { No } 242 \pm 64\end{array}$ & 0.01 \\
\hline Conditions associated with the work process & & $<0.001$ & & $<0.001$ \\
\hline Do not to have conditions associated with delays ${ }^{\mathrm{a}}$ & $81 \pm 8$ & & $61 \pm 13$ & \\
\hline NET postponed by the physician & $160 \pm 67$ & 0.12 & $63 \pm 19$ & 0.94 \\
\hline Time for sending the first diet by the central kitchen & $457 \pm 68$ & $<0.001$ & $210 \pm 50$ & $<0.001$ \\
\hline Diet was not installed & $188 \pm 95$ & 0.10 & $234 \pm 111$ & $<0.001$ \\
\hline Fasting for therapeutic or diagnostic procedures & $452 \pm 104$ & $<0.001$ & $344 \pm 78$ & $<0.001$ \\
\hline
\end{tabular}

Note: NET = Nasoenteral tube; $M V=$ Mechanical ventilation; NIMV = Non-invasive mechanical ventilation; ENT = Enteral nutritional therapy; aReference range. Gross time derives from univariate analysis, and the adjusted time derives from multivariate analysis. Data expressed in "mean \pm Standard Error" of gamma distribution, in minutes.

\section{DISCUSSION}

This study identified a longer time between the indication and the use of NET, which can exceed 10 hours in $50 \%$ of patients. In addition, an evaluation of the intermediate stages of the process shows that factors related to the organization of the assistance and the condition of the patient contribute to the increase in time.

The literature presents few results of studies evaluating the entire process from indication to the use of enteral tubes, especially in emergency settings, which makes comparison of the results found difficult. In a single study ${ }^{(13)}$ that evaluated registers of 1,822 insertions of NET in 729 adult patients in a North American tertiary hospital, the authors reported an average time between the indication of the need for a tube and the administration of the first diet of $375 \pm 724$ minutes (minimum, 6; maximum, 5,760). The same authors also presented the differences in time in the stage between the indication and the insertion of tubes: $80 \pm 193$ minutes (minimum, 8; maximum, 2,980), times that are higher than that evidenced in the present study. It is noticed that, such as in our results, there was great variability in the times involved between the indication and administration of the first diet, or until the insertion of the tube. However, differences in the design (retrospective character and absence of analysis of the clarifying factors of time) and presentation of the results (adoption of average and its measure of dispersion, despite the enormous variability) limit the generalization of the findings of that publication.

In the stage between the indication and the insertion of tubes, it was verified that verbal communication among the members of the team can bring the performance of the assistance actions forward, but there is a potential risk of incidents or adverse events related to the adoption of "verbal prescription." (15-16) This modality should be used exclusively in situations of imminent risk to life ${ }^{(15-16)}$. Even so, the practice of "verbal prescription" out of conditions of urgent care, as in the indication of NET insertion, is more frequent than would be desired. In a study ${ }^{(16)}$ performed in different units of a hospital in the United States, the authors identified 1,522 "verbal prescriptions" in seven days of follow-up. Most of them (62\%) related to a change in the diet, requests for examinations, and other procedures; the others were related to medication administration.

The prescription and insertion of NET during the night shift were also associated with delays in the process, which can be partially explained by the reduction in the number of nurses. The consequences in terms of the reduction of the nursing work conditions have already been reported in the literature ${ }^{(17-18)}$. In a study ${ }^{(17)}$ performed in two large hospitals in Japan, 357 nurses answered about the conditions that could affect productivity and cause incidents and delays related to healthcare. Of the total of 2,150 people/day, the reduction in the number of nurses on the night shift, and the consequent greater rate of patients per professional, fatigue and sleep were pointed to as responsible for affecting productivity and increasing the risk of incidents. When evaluating delays, the authors used statistics that were similar to those adopted in the present study, and identified an association between fatigue (OR: 1.05; Cl 95\%: 1.01-1.09) and work load (OR: 1.05; Cl 95\%: 1.02-1.08) in the delays in assistance.

In research ${ }^{(19)}$ performed in the admission units of the same hospital headquarters as the present study, adopting the same statistics, it was identified that the increase in the number of patients per nursing professional is associated with an increase in the rates of falls from bed, venous catheter-related bloodstream infections, and absenteeism. Although postulated that a worse rate of patients per nursing professional or other professionals (radiology technicians, nutrition attendants) would be associated with delays in the process of indication of tube use, this hypothesis was not confirmed in any of the stages. In fact, the care units included in the previously cited study ${ }^{(19)}$ have a fixed number of patients, which does not happen in the emergency department, where overcrowding is a constant. Also, the types of outcomes evaluated, which were not about delays in unit of time (minutes), can explain the difference among these findings.

There was more agility between the insertion of the tube and the X-ray when the clinical test (auscultation test) left doubts regarding the NET's position. Tests at the bedside can be insufficient to confirm the tube position. In this regard, a 
study ${ }^{(20)}$ performed in the intensive care unit evaluated the consistency between the auscultation test and the X-ray in the localization of the distal tip of the NET. Of the 80 insertions, two conditions of risk were not identified through the auscultation test: a tube located in the right bronchus and one in the distal third of the esophagus. The authors highlight the risk of severe events in case the X-ray is not performed, because this examination is the reference standard and should be carried out in all insertions ${ }^{(1-2)}$. It is important to highlight that the request for an X-Ray to confirm the position of the tube is assured for the Brazilian nurse ${ }^{(1-2)}$, although this practice is attributed to the physician in a large extent of the services. Nurses have to know their attributions in the care process of the patient in use of enteral nutrition, and acquire the necessary abilities for the safe exercise of the profession.

In all stages, the patients who sought the service specifically for changing or reinserting a tube had significantly lower times compared to the others. However, they compete for the attention of the professionals and for resources with other patients admitted for different reasons. In the hospital headquarters of the present study, patients using NET at home that need to change or to reinsert the device can make appointments for the procedure in a specific clinic that attends during two afternoons per week, which may have contributed to the fact that only $3.3 \%$ of the insertions evaluated were reinsertions.

In research ${ }^{(21)}$ conducted in a Chinese emergency service that treats clinical and surgical patients, nurses identified that about six to eight patients per month sought the service specifically for NET reinsertion. The authors compared two groups of patients. In the one that employed conventional treatment ( $n=12$ ), similarly to the process adopted in the emergency department of the present study, the patients were given a consult, had a prescription for tube insertion, were referred to the nurse for the procedure, and returned to the doctor for release of use of the tube. In the intervention group ( $n=10)$, the nurses performed the insertion procedure, tested the position of the tube through $\mathrm{pH}$ test (hydrogen ionic procedure) and, in case of doubt, requested the X-ray. However, the physician's opinion was also necessary for release of tube use. The time between the arrival and insertion of the tube was significantly lower in the intervention group (32, IQR: 23.8-67.5 minutes versus 111, IQR: 55.8-177.8 minutes; $p=0.003)$. The authors highlighted the importance of maintaining a specific protocol to make the healthcare professional aware of the importance of restoring EN as soon as possible through the release of these patients after the confirmation of the adequate position of the tube.

Finally, from the release to the use of NET to the administration of therapy, factors such as the work shift, patients' conditions, and care processes were associated with longer times. In the emergency department that hosted this study, there is a routine of rounds for discussing the cases that, for the majority of patients, occupies almost the totality of the morning shift. Only in the end of the morning are the deliberations, including those related to NET (release for use of the tube and beginning of enteral nutrition), shared with the other members of the care team, which can partially explain the longer times in this shift.
The maintenance of fasting for procedures or for delays in the routines was equally associated with higher delay between the release and the use of the tube. Studies ${ }^{(22-24)}$ have demonstrated damage, mainly for critically ill patients, when they are kept on fasting or nil per tube, which is explained by their clinical instability. A meta-analysis ${ }^{(23)}$, carried out to evaluate whether there are benefits to keeping post-operative patients fasting, included 837 patients who underwent GIT surgery. Groups of patients who received $\mathrm{EN}$ in the first 24 hours after the procedure were compared to those who were fasting. The authors stated that the benefits of fasting in the GIT postoperative period are not clear, because early EN was demonstrated to reduce the risk of any type of infection (RR: $0.72 ; \mathrm{Cl} 95 \% 0.54-0.98$ ) and the time of hospital stay (RR: $0.84 ; \mathrm{Cl} 95 \% 0.36-1.33$ ), although there was an increased risk of vomiting (RR: 1.27; Cl 95\% 1.01-1.61).

Different publications ${ }^{(8-9,25)}$ evaluated the early protective effect (24-48 hours) of an enteral diet in patients admitted to intensive care centers who were habitually on vasopressor drugs and on ventilatory support, originating formal guidelines for this practice ${ }^{(8-9)}$. In the present study, the patients allocated to the room for critical patients, vasopressor drug users, and users of ventilatory support followed the recommendation for their patients. The challenge seems to be to establish and follow goals for the beginning of NET in patients with no need for intensive support, although they are admitted at the emergency departments.

To minimize process-related delays, such as those observed in this last stage, researchers ${ }^{(26-27)}$ favor the applicability of the concepts of automation in a hospital environment, not only for activities such as laboratory flows and resource management, for instance, but also to guarantee that the flow of attendance for patients and communication among the professionals are safer, more economic, and efficient. In this context, ready-foruse diets (closed system) could be configured as alternatives.

\section{Study limitations}

Although cohort studies, especially those of contemporary temporality, are the best designs to understand the independent effect of outcome predictors, variables that were not expected in the planning cannot be analyzed. In addition, causal inference can frequently be influenced by confounding variables. A great number of process- and patient-related variables were evaluated in this study, what resulted in a great number of variables at the beginning of the statistical modeling process for the number of tube insertions in question. However, all of the analysis was conducted with the observation of stability and adjustments of the models to assure that the number of observations allowed for the proposed inferences. A possible limitation of the present study is inherent in the observational studies, in which the presence of the team of researchers can influence the assistance routine, so as to bring the actions related to tube ENT forward. However, this condition was minimized when the first observations were discarded. Another limiting factor was the study was conducted in only one center, which does not allow the generalization of the data for other services; however, this study was the first one to try to analyze the process between the indication and the use of NET, using robust design and statistical analysis. 
Contributions for the fields of nursing, health, or public policy

The findings of the present study can subsidize the adoption of a new indicator of quality of care for patients requiring tube ENT-namely the time between indication and use of the enteral tube and its substages. Similarly, this study leads to the consideration of nursing care for patients on ENT with due emphasis on the treatment, making it equal to the other care demands. In addition, as other care behaviors are guided by protocols and checklists, so that the process occurs in a more agile and, mainly, safe way, their creation seem necessary in the process of tube ENT. Thus, the indication of early tube ENT, the assumption of responsibility by the involved professionals, and the guarantee of fulfillment of all stages can be contemplated.

Moreover, the main contribution of this study regarding education is an alertness to the need for actions directed toward nursing technicians and nurses during their training courses. Knowing the implications of safe practices on the clinical outcomes of the patients during the technical and undergraduate courses-as well as knowing how to explore the negative effects of malnutrition, delays in the ENT, incidents between the insertion and the administration of the diet and its potential damage to the patients-can improve this situation in the near future.

Finally, within the scope of nursing research, studying actions that improve the agility of the work processes, as well as patient safety, during procedures such as the insertion and maintenance of the tube, is the main result to be pursued. Knowing, in a systematic way, by means of indicators, the expended time between the indication of the tube and the beginning of therapy makes it possible to build a historical series, as well as to adopt earlier corrective actions.

\section{CONCLUSION}

The time elapsed between the indication and use of NET in the emergency department is high, exceeding 10 hours in half of the cases. The delay, which is observed in the several stages of the process, is explained by different factors. Regarding tube insertion, while more agility was observed in the process, more delays were identified in the presence of factors related to the differences in the work processes, and in the care demands of the different shifts (morning, afternoon, and night), communication among the team (when the nurse did not receive verbal information that there was a demand for tube insertion, even though it was prescribed), use of invasive mechanical ventilation, and noradrenaline.

In addition to these factors, other delays in the work process, such as the delay in the distribution of the diet and its installation, or fasting by the patient before procedures, contributed to the increment of time at each stage and, consequently, to the total time between the indication and use of the tube. Identifying the main determinants of delays allows for actions to be planned in terms of the modifiable factors of the process. Thus, the adoption of checklists that improve the agility and safety of this process seems appropriate.

\section{FUNDING}

This study is sponsored by the Research and Events Incentive Fund (Fundo de Incentivo à Pesquisa e Eventos - FIPE) of the Clinics Hospital of Porto Alegre.

\section{REFERENCES}

1. Conselho Federal de Enfermagem - COFEN. Resolução COFEN № 453 DE 16 de janeiro de 2014[Internet]. 2014 [cited 2016 May 15]:1-9. Available from: http://www.legisweb.com.br/legislacao/?id =264977.

2. Brasil. Ministério da Saúde. Agencia Nacional de Vigilância Sanitária. Resolução RDC n 63, de 06 de julho de 2000. Diário Oficial da União[Internet]. Poder Executivo, de 29 de junho de 2000 [cited 2016 May 15]. Available from: http://e-legis.anvisa.gov.br/leisref/public/ showAct.php?id $=17610 \&$ word

3. Graciano RDM, Ferretti REL. Nutrição enteral em idosos na unidade de terapia intensiva: prevalência e fatores associados. Geriatr Gerontol. 2009;2(4):151-5.

4. Martins AS, Rezende NA, Torres HEG. Sobrevida e complicações em idosos com doenças neurológicas em nutrição enteral. Rev Assoc Med Bras[Internet]. 2012[cited 2016 May 15];58(6):691-7. Available from: http://www.scielo.br/pdf/ramb/v58n6/v58n6a14.pdf

5. Methenya NA, Meertb KL, Clouse RE. Complications related to feeding tube placement. Curr Opin Gastroenterol. 2007;23(2):178-82.

6. Sparks DA, Chase DM, Coughlin LM, Perry E. Pulmonary complications of 9931 narrow-bore nasoenteric tubes during blind placement: a critical review. JPEN J Parenter Enteral Nutr[Internet]. 2011[cited 2016 May 15];35(5):625-9. Available from: http:// pen.sagepub.com/content/35/5/625.full.pdf + html

7. Sorokin R, Gottlieb JE. Enhancing Patient Safety During Feeding-Tube Insertion: a review of more than 2000 insertions. JPEN J Parenter Enteral Nutr. 2006; 30(5):440-5.

8. Waitzberg DL, Enck CR, Miyahira NS, Mourão JRP, Faim MMR, Oliseski M, Borges A. Sociedade Brasileira de Nutrição Parenteral e Enteral (SBNPE) e Associação Brasileira de Nutrologia. Projeto Diretrizes. Terapia Nutricional: Indicadores de Qualidade[Internet]. 2011[cited 2016 May 15]. Available from: http://www.projetodiretrizes.org.br/9_volume/terapia_nutricional_indicadores_de qualidade.pdf

9. Taylor BE, McClave SA, Martindale RG, Warren MM, Johnson DR, Braunschweing C et al. Guidelines for the Provision and Assessment of Nutrition Support Therapy in the Adult Critically III Patient: Society of Critical Care Medicine (SCCM) and American 
Society for Parenteral and Enteral Nutrition (A.S.P.E.N). Crit Care Med[Internet]. 2016[cited 2016 May 15];44(2):390-438. Available from: http://pen.sagepub.com/content/33/3/277.full.pdf + html

10. Bankhead R, Boullata J, Brantley S, Corkins M, Guenter P, Krenitsky J, et al. Enteral Nutrition Practice Recommendations. JPEN J Parenter Enteral Nutr[Internet]. 2009[cited 2016 May 15];33(2):122-67. Available from: http://pen.sagepub.com/content/early/2009/01/27/0148607108330314.full.pdf +html

11. Kuo S, Rhodes RL, Mitchell SL, Mor V, Teno JM. Natural history of feeding-tube use in nursing home residents with advanced dementia. J Am Med Dir Assoc[Internet]. 2009[cited 2016 May 15];10(4):264-70. Available from: http://www.jamda.com/article/ S1525-8610(08)00412-X/pdf

12. Hoot NR, Aronsky D. Systematic Review of Emergency Department Crowding: Causes, Effects, and Solutions. Ann Emerg Med. 2008; 52(2): 126-36.

13. De Aguilar-Nascimento JE, Kudsk KA. Clinical Costs of Feeding Tube Placement. JPEN J Parenter Enteral Nutr. 2007;31(4):269 -73.

14. Guimarães LSP, Hirakata VN. Uso do Modelo de Equações de Estimações Generalizadas na análise de dados longitudinais. Rev HCPA[Internet]. 2012[cited 2016 May 15];32(4):503-11. Available from: http://seer.ufrgs.br/index.php/hcpa/article/view/36971/23993

15. Wakefield DS, Wakefield BJ. Are verbal orders a threat to patient safety? Postgrad Med J[Internet]. $2009[$ cited 2016 May 15];18(3):165-8. Available from: http://qualitysafety.bmj.com/content/18/3/165.full.pdf + html

16. Wakefield DS, Brokel J, Ward MM, Schwichtenberg T, Groath D, Kolb M, et al. An exploratory study measuring verbal order content and contexto. Qual Saf Health Care. 2009;18 (3):169-73.

17. Seki, Y. Working Condition Factors Associated with Time Pressure of Nurses in Japanese Hospitals. J Occup Health[Internet]. 2008[cited 2016 May 15];50(2):181-90. Available from: https://www.jstage.jst.go.jp/article/joh/50/2/50_L7031/_pdf

18. Wise S, Fry M, Duffield C, Roche M, Buchanan J. Ratios and nurse staffing: The vexed case of emergency departments. Australas Emerg Nurs J. 2015 Feb;18(1):49-55.

19. Magalhães AMM, Dall'Agnol CM, Marck PB. Nursing workload and patient safety - a mixed method study with an ecological restorative approach. Rev Latino-Am Enfermagem[Internet]. 2013[cited 2015 Dec 07];146-54. Available in: http://www.scielo.br/ $\mathrm{pdf} / \mathrm{rlae} / \mathrm{v} 21 \mathrm{nspe} / 19 . \mathrm{pdf}$

20. Beghetto MG, Anziliero F, Leães DM, De Mello ED. Feeding tube placement: auscultatory method and x-ray agreement. Rev Gaúcha Enferm[Internet]. 2015[cited 2015 Dec 28];36(4):98-103. Available in: http://seer.ufrgs.br/index.php/RevistaGauchadeEnfermagem/ article/view/54700/35677

21. Yan $\mathrm{Ho} \mathrm{CH}$, Hainder $\mathrm{TH}$, Grahan $\mathrm{CA}$. Nurse initiated reinsertion of nasogastric tubes in Emergency Department: a randomised controlled trial. Australas Emerg Nurs J. 2013;16(4):133-46.

22. De Aguilar-Nascimento JE, Bicudo-Salomao A, Portari-Filho PE. Optimal timing for the initiation of enteral and parenteral nutrition in critical medical and surgical conditions. Nutrition. 2012; 28(9):840-3.

23. Lewis SJ, Egger M, Sylvester PA, Thomas S. Early enteral feeding versus "nil by mouth" after gastrointestinal surgery: systematic review and metaanalysis of controlled trials. BM][Internet]. 2001[cited 2016 May 15];323(7316):773-76. Available from: http://www.bmj.com/ content bmj/323/7316/773.full.pdf

24. Leong AY, Cartwright KR, Guerra GG, Joffe AR, Mazurak VC, Larsen BM. A Canadian Survey of Perceived Barriers to Initiation and Continuation of Enteral Feeding in PICUs. Pediatr Crit Care Med.2014;15(2):49-55.

25. Heyland DK, Stephens KE, Day AG, McClave SA.The success of enteral nutrition and ICU-acquired infections: a multicenter observational study. Clin Nutr. 2011;30(2):148-55.

26. Ng D, Vail G, Thomas S, Schmidt N. Applying the Lean principles of the Toyota Production System to reduce wait times in the emergency department. CJEM. 2010;12(1):50-7.

27. Buzzi D, Plytiuk CF. Pensamento enxuto e sistemas de saúde: um estudo da aplicabilidade de conceitos e ferramentas lean em contexto hospitalar. Rev Qualid Emergente[Internet]. 2011[cited 2016 May 15]; 2(2): 18-38. Available from: http://revistas.ufpr.br/qualidade/article/ view/25187/16832 